\title{
Microwave Radiometry for Oil Pollution Monitoring, Measurements, and Systems
}

\section{Skou, Niels}

\section{Published in:}

I E E E Transactions on Geoscience and Remote Sensing

Link to article, DOI:

10.1109/TGRS.1986.289593

Publication date:

1986

Document Version

Publisher's PDF, also known as Version of record

Link back to DTU Orbit

Citation (APA):

Skou, N. (1986). Microwave Radiometry for Oil Pollution Monitoring, Measurements, and Systems. I E E E Transactions on Geoscience and Remote Sensing, GE-24(3), 360-367.

https://doi.org/10.1109/TGRS.1986.289593

\section{General rights}

Copyright and moral rights for the publications made accessible in the public portal are retained by the authors and/or other copyright owners and it is a condition of accessing publications that users recognise and abide by the legal requirements associated with these rights.

- Users may download and print one copy of any publication from the public portal for the purpose of private study or research.

- You may not further distribute the material or use it for any profit-making activity or commercial gain

- You may freely distribute the URL identifying the publication in the public portal 


\title{
Microwave Radiometry for Oil Pollution Monitoring, Measurements, and Systems
}

\author{
NIELS SKOU, MEMBER, IEEE
}

\begin{abstract}
Work is presently carried out in Europe to change the status of the microwave radiometer, namely, to develop it from a research instrument to an operational instrument-especially for measuring oil pollution on the sea surface. The Technical University of Denmark (TUD), with its long experience in airborne microwave radiometry, is heavily involved in this process. The TUD multichannel imaging radiometer system has been flown in several large-scale oil-pollution experiments, the collected data have been analyzed, and they have revealed that care must be exercised to obtain accurate oil volume estimations. Computer simulations of the total measurement situation have shown how the observed difficulties come about and have indicated the countermeasures to apply. Based on the above-mentioned exercises, optimum (and practical) systems are being developed.
\end{abstract}

Index Terms-Remote sensing, microwave radiometry, oil pollution, oil spill volume.

\section{INTRODUCTION}

$\mathrm{T}$ HE TECHNICAL University of Denmark (TUD) has lately participated in oil-spill remote-sensing experiments with its airborne multifrequency imaging radiometer system-originally developed for sea ice investigations in the arctic region. Side-looking radars and multispectral scanners offer great potential for detection and mapping of oil spills on the sea, but the microwave radiometer offers a unique potential for the determination of oil-slick thickness, hence eventually total oil volume within the slick [1]-[3]. So, there is at present within Europe a great interest in turning the microwave radiometer from a research instrument into an operational oil mapping and quantifying instrument.

Steps on the path of development have been the execution of large-scale experiments, in which known quantities of oil were spilled at sea to be measured by a variety of sensors, including the TUD radiometers.

In September 1982 the Institut Francais du Pétrole carried out their Protecmar 82 oil-spill experiment in collaboration with the Joint Research Centre (JRC) of the Commission of the European Communities. Through JRC, TUD participated in this experiment. Five cubic meters of oil were released from a ship to initially cover roughly $10 \mathrm{~m} \times 2000 \mathrm{~m}$. This very thin and well controlled slick was sensed by the TUD radiometers, and on three different passes the total oil volume was measured to $5.6 \mathrm{~m}^{3}$, $6.6 \mathrm{~m}^{3}$, and $5.8 \mathrm{~m}^{3}$.

Manuscript received September 12, 1985; revised October 31, 1985.

The author is with the Technical University of Denmark, Lyngby, Denmark.

IEEE Log Number 8607735.
Having experienced such rather pleasing results, the ardour was great to carry out new exercises with larger oil volumes and larger thickness variations to assess the accuracy of volumetric determinations under more realistic circumstances.

In October 1983 the JRC carried out their Archimedes 83 experiment in which numerous sensors mounted on 8 aircraft took part. The TUD radiometers measured the 40$\mathrm{m}^{3}$ pure-oil release of that experiment, and consistent underestimations of the volume were noticed. The measurements will be described, and a discussion of the results will be carried out in the following sections.

\section{Sensing of Oil Films by Microwave RADIOMETRY}

The brightness temperature of the oil-covered sea can be calculated using standard techniques from electromagnetic theory regarding transmission through and reflection from a medium, covered by a dielectric plate. A computer program, based on [4], has been written, and the brightness temperature of the oil slick has been calculated as a function of slick thickness. Fig. 1 shows curves corresponding to frequencies, incidence angles, and polarizations of the TUD radiometer system:

$\begin{array}{lccc}\text { Frequency: } & 5 \mathrm{GHz} & 17 \mathrm{GHz} & 34 \mathrm{GHz} \\ \text { Polarization: } & \mathrm{H} & \mathbf{H} & \mathrm{H} \\ \text { Angle of incidence: } & 41^{\circ} & 54^{\circ} & 50^{\circ} \\ \epsilon \text { (sea water): } & 63+j 38 & 39+j 37 & 20+j 30\end{array}$

The dielectric constant $(\epsilon)$ of sea water is calculated after [5] and corresponds to a salinity of $39 \% 0$ and a sea temperature of $20^{\circ} \mathrm{C}$. The dielectric constant of oil is taken as $2+j 0.01$, which is a typical value from the literature.

It is seen that a $34-\mathrm{GHz}$ channel alone gives good resolution of thin layers, but less than $2 \mathrm{~mm}$ can be measured unambiguously. A $17-\mathrm{GHz}$ channel alone can measure up to $3.5 \mathrm{~mm}$ of oil, but with poor resolution below $1 \mathrm{~mm}$. A combined 17- and $34-\mathrm{GHz}$ system of course combines the merits of each channel and is able to measure slick thicknesses up to $3.5 \mathrm{~mm}$ with good accuracy throughout the range.

The addition of a 5-GHz channel to this system extends the measurement range up to $12-13 \mathrm{~mm}$ : The high-frequency channel still measures the thickness with good resolution, while the low-frequency channel solves the ambiguity problem. 


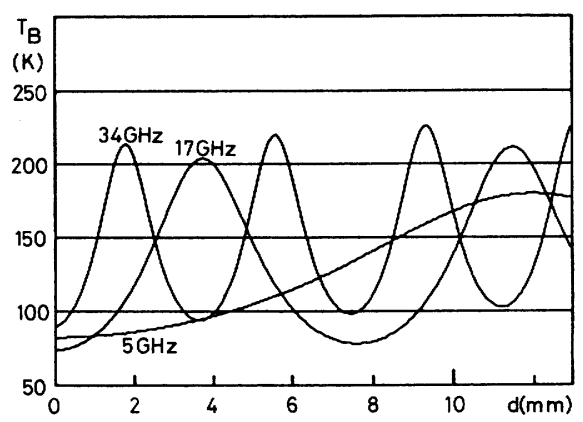

Fig. 1. Brightness temperature as a function of oil slick thickness.

The preceding considerations assume an extended uniform layer of oil on the sea surface. In the case of thickness variations on a scale smaller than the radiometer antenna's field-of-view, this measures some averaged value of the brightness temperatures in question. In this context it is important to note that the relationship between brightness temperature and slick thickness is far from being linear.

\section{The Radiometer System}

The TUD radiometer system comprises:

1) an imaging multifrequency antenna with conical scan,

2) receivers at 5,17 , and $34 \mathrm{GHz}$,

3) digital processing and control units,

4) digital tape recorders (CCT), and

5) real-time false-color display.

The antenna is based on a 1-m-aperture offset parabolic reflector, viewed by 3 vertical horns. The reflector scans sinusoidally around a vertical axis. The radiometer receivers are of the noise-injection type with a noise figure of $5 \mathrm{~dB}$. The sensitivity is $1 \mathrm{~K}$ for $8 \mathrm{~ms}$ integration time.

The antenna and the receivers are pallet mounted and positioned on the loading ramp of a C-130 aircraft. The ramp is lowered to its horizontal position when measurements are to be taken, and the antenna has an unobstructed view of the scene below and aft of the aircraft.

The radiometer system is designed to give contiguous coverage (imaging mode) down to a flight altitude of 1000 $\mathrm{m}$ above ground level. In profiling mode, that is, the antenna fixed looking straight aft, altitudes of $100 \mathrm{~m}$ are feasible (resulting in improved ground resolution).

Additional information on the system, as configurated for the present task, is given in Table I.

\section{THE 1983 EXPERIMENT}

On Friday, October 21, 1983, an oil spill was made during the early morning in the North Sea off the coast of Holland. Forty cubic meters of fuel oil $(750 \mathrm{cST})$ were dumped into the sea and left for $1 \frac{1}{2}$ days to undergo natural spreading before being recovered by Dutch authorities (Rijkswaterstaat). The weather was fair with winds below 16 knots. In the following will be presented examples of the radiometer results from three overflights: one around
TABLE I

\begin{tabular}{|c|c|c|c|}
\hline Frequency & $5 \mathrm{GHz}$ & $17 \mathrm{GHz}$ & $34 \mathrm{GHz}$ \\
\hline Bandwidth & : $500 \mathrm{MHz}$ & $1 \mathrm{GHz}$ & $1 \mathrm{GHz}$ \\
\hline Polarization & : horizontal & horizontal & horizontal \\
\hline Angle of incidence & e: $\quad 41^{\circ}$ & $54^{\circ}$ & $50^{\circ}$ \\
\hline Ft. print $(1000 \mathrm{~m})$ & $160 \times 248 \mathrm{~m}$ & $47 \times 73 \mathrm{~m}$ & $24 \times 37 \mathrm{~m}$ \\
\hline Ft. print $(100 \mathrm{~m})$ & $16 \times 25$ & $4.7 \times 7.3 \mathrm{~m}$ & $2.4 \times 3.7 \mathrm{~m}$ \\
\hline
\end{tabular}

$12.00 \mathrm{Z}$, another around $17.00 \mathrm{Z}$ (both on the day of the spill), and one the next morning around $10.00 \mathrm{Z}$. Imagery from all three flights will be shown, while only one profile from the last flight is presented. Due to a failing $17-\mathrm{GHz}$ local oscillator, recordings were only made at 5 and 34 $\mathrm{GHz}$ during the entire experiment.

\section{A. The Imagery}

In Fig. 2 is shown a color photograph of the three examples of imagery to be discussed in the following. The original $34-\mathrm{GHz}$ data have been processed for oil thickness by computer mapping according to a piece-wise linear approximation to the first ascending part of the 34$\mathrm{GHz}$ curve in Fig. 1. Each pixel shows the average thickness of the oil layer within that pixel according to the color code at the bottom of the photo. The width of one image is $500 \mathrm{~m}$. Headings are: 52, 179, 180 "flying" from bottom to top of the images. Pixels are $10 \times 10 \mathrm{~m}$.

By an integration over the image, the total amount of oil is found as measured on the three different passes: 17 , 32.5 , and $32 \mathrm{~m}^{3}$, and the results are printed under each pass.

At $34 \mathrm{GHz}$ the brightness temperature increase over the oil never exceeded some $20 \mathrm{~K}$, indicating that the mapping to oil thickness should be safe: As Fig. 1 shows, ambiguity problems are not expected until increases in the order of $100 \mathrm{~K}$ are noticed. The $5-\mathrm{GHz}$ channel only showed marginal responses to the oil film-still too thin/ small for this relatively low frequency.

From the three sequential images it is clear how the oil spreads out to cover larger and larger areas as time passes. Actually, it is not certain that the whole oil slick was encompassed by the 500-m swath of the radiometer system on the last pass. It is clear that a noticeable underestimation of oil volume takes place, especially in the first example where the spreading is still limited and the oil assumes its largest thickness values.

\section{B. The Profiles}

In Fig. 3 is shown an example of the profiles obtained during the mission. The brightness temperature as measured by the two operating channels is shown on a relative scale. Note the $50-\mathrm{K}$ bar to the left in the figure. On the right-hand side of the figure are shown oil thickness scales for the frequencies as calculated from Fig. 1. From the low altitudes of $100 \mathrm{~m}$, the spatial resolution of the $5-\mathrm{GHz}$ radiometer is adequate to ensure reasonable antenna beam filling factors when observing the patches of thicker oil. It is evident that the $5-\mathrm{GHz}$ channel reads much larger oil 


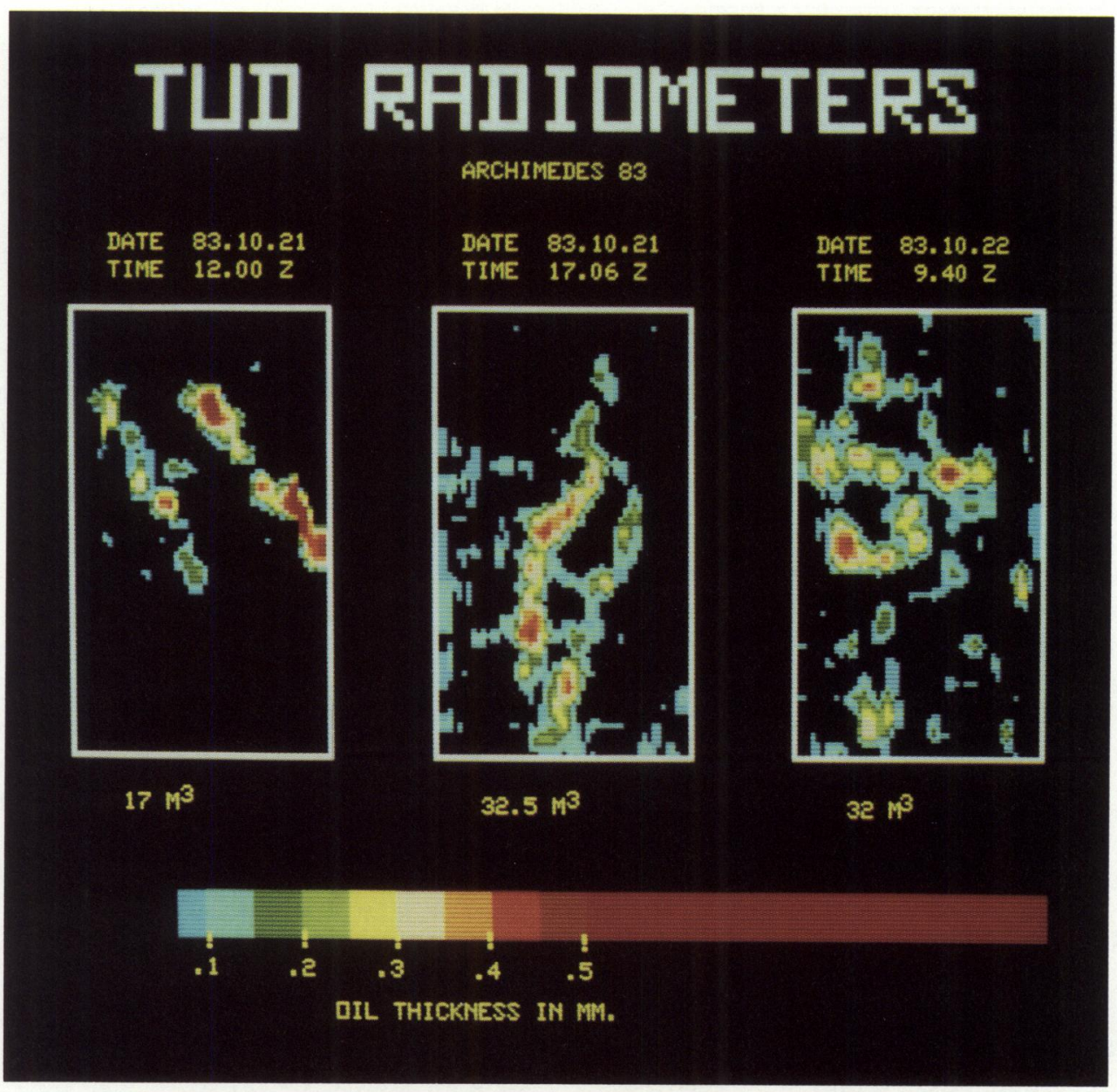

Fig. 2. Oil thickness coded imagery from the 83 experiment.

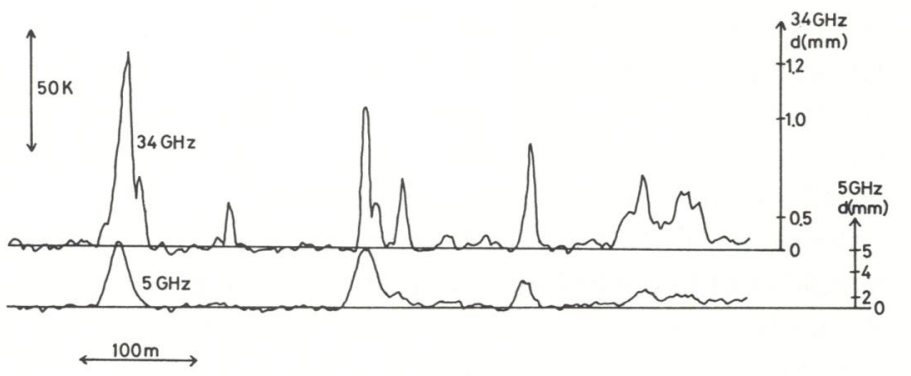

Fig. 3. Profile from 83.10 .22 at $10.07 \mathrm{Z}$.

thicknesses than the $34-\mathrm{GHz}$ channel. Likewise, it is evident that the $34-\mathrm{GHz}$ channel never reaches its maximum reading of some $120-\mathrm{K}$ brightness temperature increase, which would be expected for the apparently thick oil in question-and which would indicate that this channel was approaching its ambiguity range. Similar observations and some discussion thereof are found in [6].

\section{Computer Simulations of the Measurement SitUATION}

During the discussions in the previous section, two problems were pointed out: For relatively thick oil layers, the $5-\mathrm{GHz}$ channel reads much larger thicknesses than the
34-GHz channel (profiles), and the estimation of total oil volume based on 34-GHz imagery suffers (in some cases severely) underestimation-in both cases without the 34$\mathrm{GHz}$ brightness temperature approaching its theoretical maximum as a sign of caution. In the following, computer simulations of the measurement situation will show how these discrepancies between our expectations and real measurements can come about.

For simplicity, a two-dimensional model is adopted, but the conclusions drawn from that are directly applicable to the three-dimensional case qualitatively. The computer program works in four major steps and the output curves (see Fig. 4) are directly related to those:

1) The user defines the input scenario, that is, the oil thickness distribution, and this is displayed as the upper curve. Thickness $D(0-5 \mathrm{~mm})$ is a function of $N(0-250)$, which could be regarded as distance in meters. The total "volume" is calculated as the integral of the thickness distribution over $N$ and printed as "TOT."

2) Using the methods that also underlie Fig. 1, the program calculates the brightness temperature as a function of $N$ and this is displayed as curve 2 (TB in degrees Kelvin). $T B$ is the brightness temperature increase over oil compared to that of the unpolluted sea.

3) A simplified, but realistic, antenna pattern (cosine 


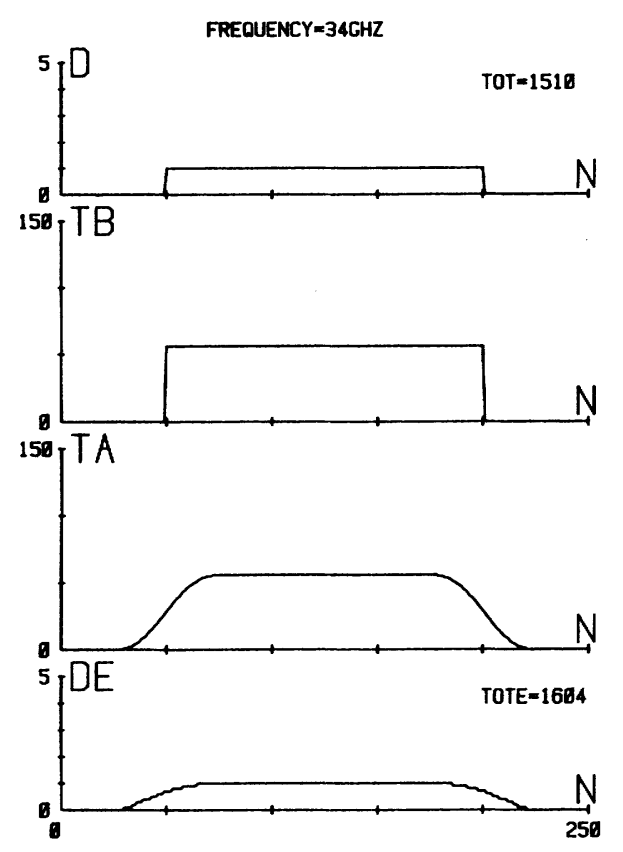

Fig. 4. Computer simulation of the measurement situation 1 .

squared power pattern) is swept across the brightness temperature scenario resulting in the measured antenna temperature curve $T A$ (in degrees Kelvin) shown as curve 3. This process is simply the convolution of the antenna pattern and the brightness temperature distribution. The 3$\mathrm{dB}$ " foot-print" of the antenna is $30 \mathrm{~m}$.

4) A piece-wise linear approximation to Fig. 1 is then used to calculate the estimated oil thickness $D E$ as a function of $N$ (curve 4 ). The estimated total "volume" (TOTE) is calculated and printed.

The first example (Fig. 4) in the series of runs to be presented here represents a very simple situation and is included to show the usefulness of the model. A uniform extensive oil layer of 1-mm thickness-well below the maximum thickness to be handled unambiguously by a $34-\mathrm{GHz}$ radiometer $(1.75 \mathrm{~mm})$-is fed through the calculations. The output is an estimated thickness of also 1$\mathrm{mm}$, apart from edge effects. The total estimated "volume" is slightly too large, also due to the edge effects.

The next example (Fig. 5) is equally simple, being a case where the $34-\mathrm{GHz}$ channel clearly cannot do the job: A thickness of $3 \mathrm{~mm}$ is seriously underestimated as expected from theory.

The following examples really show what this discussion is all about, namely the beam filling process of the antenna: The antenna makes a linear average over its fieldof-view amidst unlinear processes (translation from oil thickness to brightness temperatures and back again).

In Fig. 6 an oil layer of varying, but moderate thickness is imaged by the antenna as a uniform oil layer and the estimation is fairly good. Actually, a slight overestimation takes place, due to the many "edge effects" (not resolved by the antenna, hence not noticeable in $T A$ ).

But, in Fig. 7 things start to go wrong! A larger ampli-

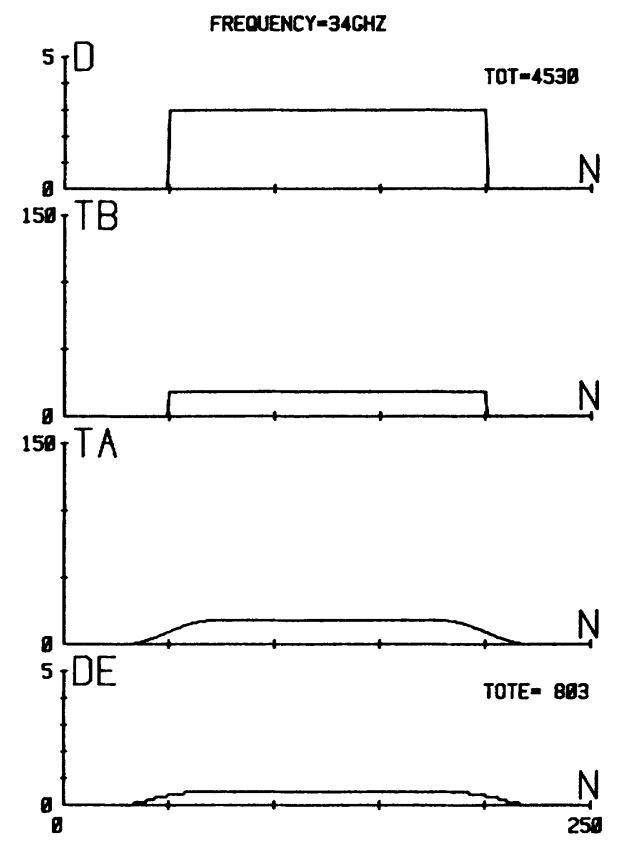

Fig. 5. Computer simulation of the measurement situation 2 .

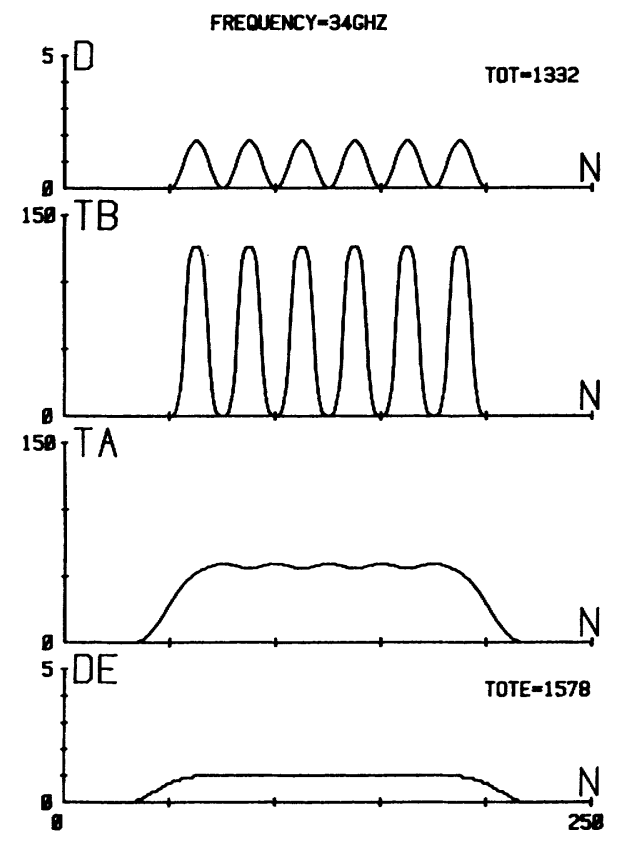

Fig. 6. Computer simulation of the measurement situation 3 .

tude in the input oil distribution function causes severe underestimation of average thickness, hence "volume." And this happens without any warning in "measured" brightness temperatures $T A$ : They stay nicely below $50 \mathrm{~K}$ !

Without changing the amount of oil but merely selecting another distribution function, things get even worse, see Fig. 8. Now the estimate is off by a factor of 4 ! The radiometer is far out in the ambiguity range without any warning in the $T A$ curve.

Fig. 9 shows the 5-GHz response to the same input scenario. Here, everything works fine as the peak input 


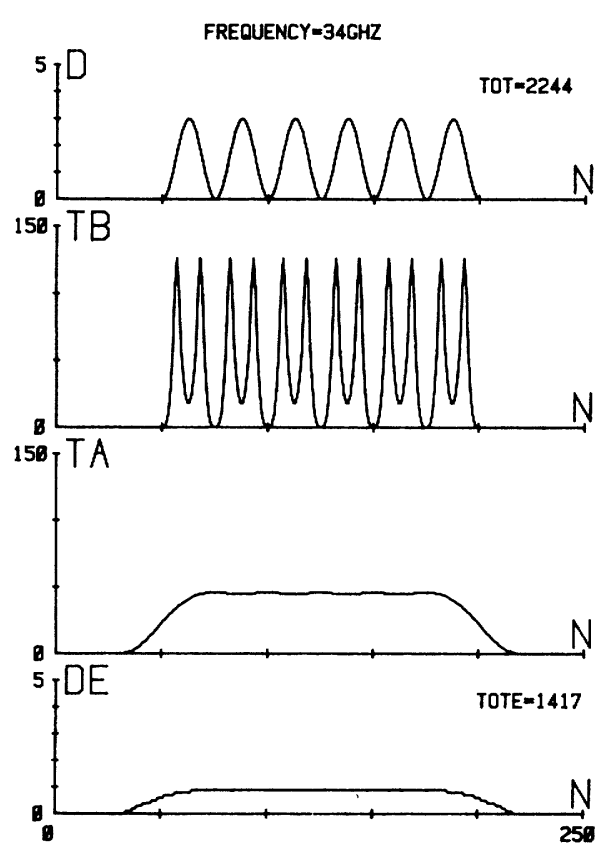

Fig. 7. Computer simulation of the measurement situation 4 .

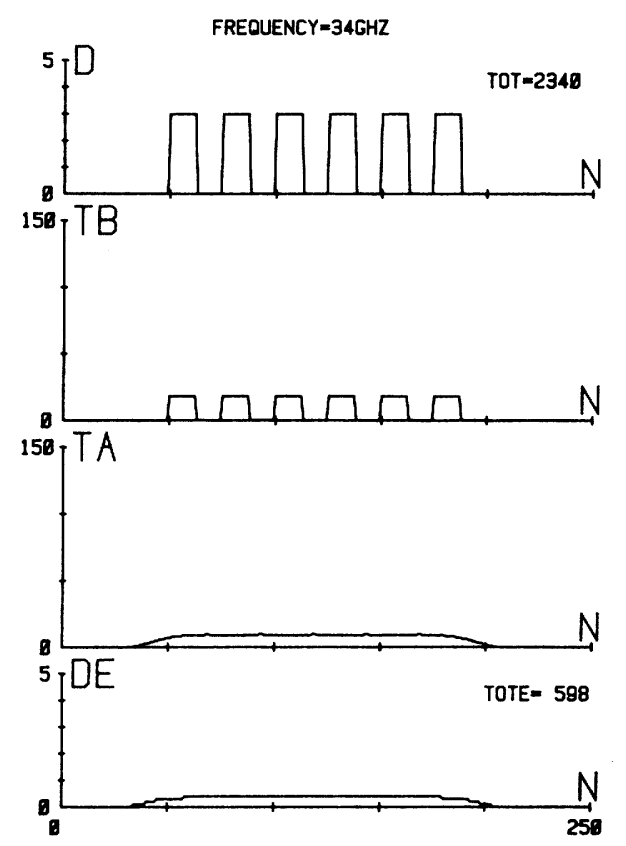

Fig. 8. Computer simulation of the measurement situation 5 .

thickness is comparatively small at this larger wavelength.

\section{Oil/Water Mixture}

The determination of oil thicknesses, hence total oil volume, from the radiometer measurements is based on Fig. 1, or rather the model behind Fig. 1. An important parameter in this model is of course the dielectric constant of the oil. The model is not extremely sensitive to this parameter, and it is allowable to use the standard value of $\epsilon=2+j 0.01$ as representative of commonly found oil dielectric constants. But if for some reason, the dielectric

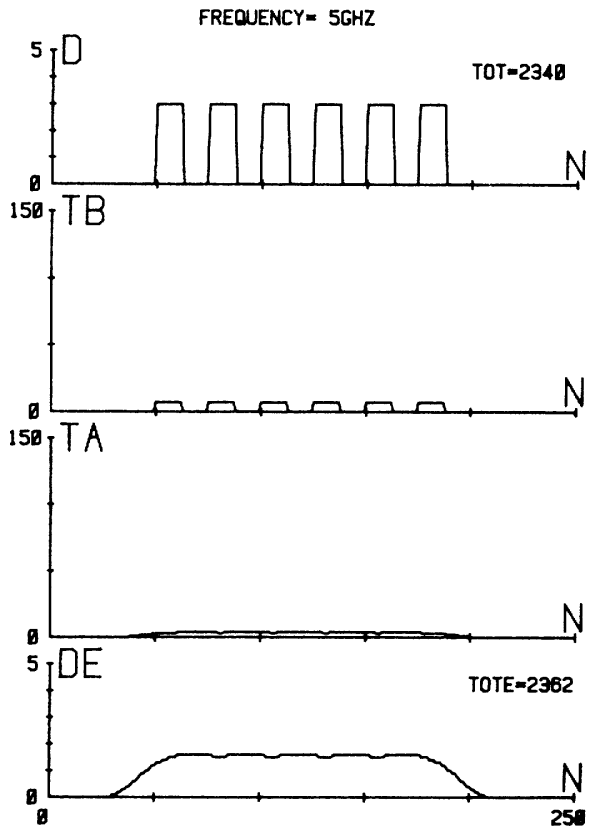

Fig. 9. Computer simulation of the measurement situation 6 .

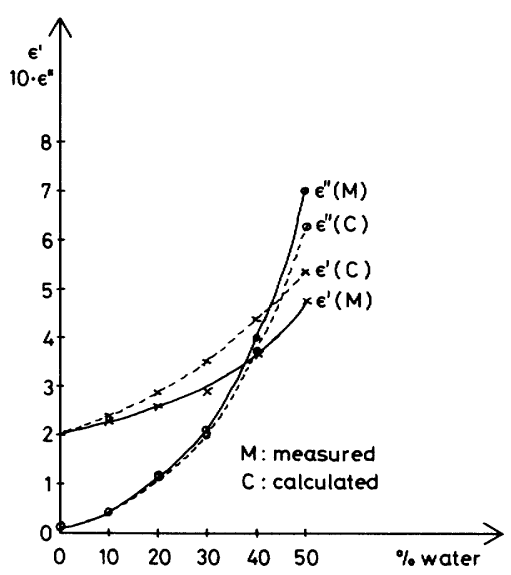

Fig. 10. Dielectric constant for oil/water mixtures as a function of water content (at $34 \mathrm{GHz}) . \epsilon=\epsilon^{\prime}+j \epsilon^{\prime \prime}$.

constant of the oil layer departs drastically from this value, say by a factor of 2 , problems arise.

It is well known that many oils are able to mix with sea water and form stable emulsions, so-called chocolate mousse. Up to at least 50-percent water content can be found in such an emulsion. It is intuitively clear that the dielectric constant of mousse with 50-percent water content cannot remain $2+j 0.01$ recalling the very large dielectric constant of sea water (see Section II).

Lääperi [6] has carried out dielectric measurements on oil/water mixtures with up to 50 -percent water content. The measurements were made around a frequency of 1 $\mathrm{GHz}$, but they can be scaled to other frequencies by taking into account the changing value of sea water's dielectric constant with frequency. (For the frequency range considered here, the dielectric constant of oil can be considered frequency independent). In Fig. 10 is shown the 


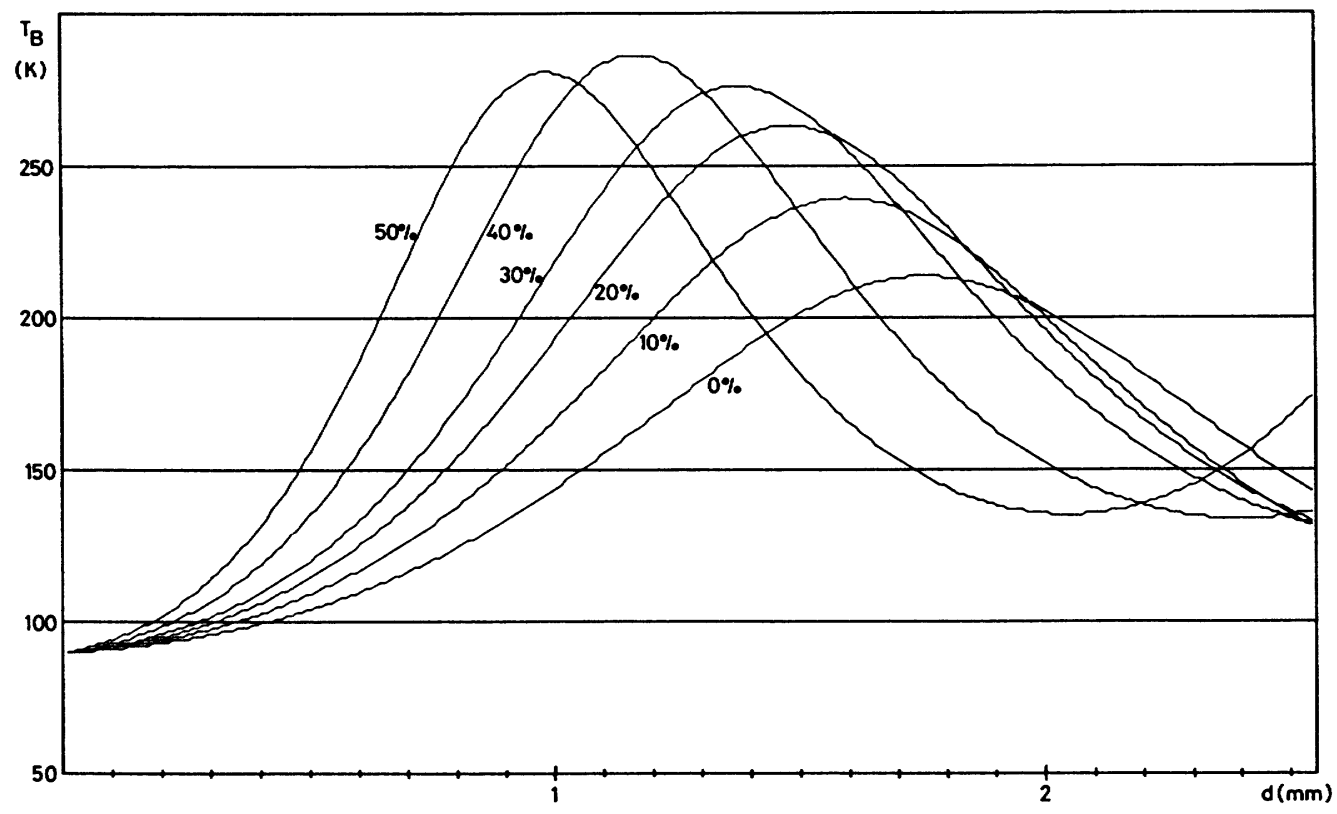

Fig. 11. 34-GHz brightness temperature as a function of oil slick thickness with water content as parameter.

dielectric constant for oil/water mixtures as a function of water content scaled to $34 \mathrm{GHz}$.

These curves are supported by theoretical considerations. The dielectric constant of a mixture, where one component serves as a continuous host material (the oil) and the other component occurs as isolated particles therein (water droplets), is given by

$$
\frac{\epsilon_{m}-1}{\epsilon_{m}+2}=\frac{\epsilon_{0}-1}{\epsilon_{0}+2} \cdot P_{0}+\frac{\epsilon_{w}-1}{\epsilon_{w}+2} \cdot P_{w}
$$

from [7] where

$\epsilon_{m}=\epsilon$ for mixture,

$\epsilon_{0}=\epsilon$ for oil $=2+j \mathbf{0 . 0 1}$,

$\epsilon_{w}=\epsilon$ for sea water $=20+j 30$,

$P_{0}$ is the oil fraction, and

$P_{w}$ is the water fraction $=\left(1-P_{0}\right)$.

Inserting known values in the above formula, a new set of curves are generated and included in Fig. 10. A nice agreement between measured and calculated values is noticed.

Again, the computer program responsible for Fig. 1 has been run, but this time with different values of dielectric constant for the oil layer corresponding to different water content in the oil, and only concerning $34 \mathrm{GHz}$. The results are shown in Fig. 11.

From the curves it is clear that the model used so far for translating measured brightness temperatures into oil thickness (based on the pure oil dielectric constant) runs into serious troubles, if the oil on the sea surface had indeed contained a large amount of water. Assume a measured brightness temperature of $180 \mathrm{~K}$. If this arises from an oil layer with 50-percent water content, this layer would have been $0.6 \mathrm{~mm}$ thick. But, our oil algorithm assumes the curve corresponding to 0-percent water contents and estimates a layer thickness of $1.3 \mathrm{~mm}$.

From this discussion two things are learned: If oil/water mixtures are formed on the sea surface as a result of an oil spill, the microwave radiometer measurements will tend to overestimate the layer thicknesses and thereby the total amount of oil. Secondly, this mechanism cannot explain the observed underestimations of oil thicknesses given special attention in this paper-on the contrary!

\section{Conclusions}

The scanning microwave radiometer has again demonstrated it ability to detect the thicker parts of an oil slick on the sea surface. Actually, the radiometer also measures the thickness of the oil in each pixel and estimation of the total oil volume is possible by integration.

An experiment carried out in 1982 , in which a rather thin well-controlled oil spill was sensed, showed excellent agreement between estimated volume and known quantity. It has always been realized that for a given frequency, this estimation accuracy is only possible within certain oil thickness limits due to ambiguity for great thicknesses. It has been anticipated that given a measurement of a large/thick oil slick, extreme brightness temperature increases would serve as a warning of possible ambiguity problems leading to severe underestimation of slick thickness, hence total volume. This is not, however, necessarily true.

In a second experiment (1983), involving a substantial $40-\mathrm{m}^{3}$ spill, the oil thickness and volume were generally underestimated by up to a factor of 2 , and the measured brightness temperatures stayed at confidently low values. The explanation to this problem is sought in the fact that the antenna makes a linear averaging over its footprint of 
the brightness temperature scenario and not of the thickness distribution-and the relationship between oil thickness and brightness temperature is far from being linear! Hence, if the spatial oil thickness distribution is not varying so slowly, that it can be regarded as almost constant on a scale equal to the footprint size (which it probably does not in real life!), inaccuracies arise. Computer simulations of the total measurement situation have been carried out, and they show how a given input oil thickness scenario may be underestimated by a factor of $2-3$, without the measured brightness temperatures reaching alarming values indicating possible ambiguity problems.

The problems of underestimation of reasonably sized slicks can be solved by simultaneous inspection of the 34$\mathrm{GHz}$ channel and some lower frequency channel. For the present slicks, a channel between 10 and $18 \mathrm{GHz}$ would probably yield a rather correct estimation. Unfortunately, only a 5-GHz channel was operative during the experiment, and this frequency is so low that the present oil slicks, although too thick for the $34-\mathrm{GHz}$ channel, were marginally thin.

From an operational point of view the benefits of even a one-frequency radiometer is clear, however. Even with possible underestimations of a factor of $2-3$, the information is useful. But, it is felt that operational radiometers should have at least two channels: One in the 30-40 $\mathrm{GHz}$ range and one in the $10-18 \mathrm{GHz}$ range.

Also from an operational point of view the imaging mode seems the most powerful: The areal extend of the oil is directly depicted in just one pass, the thickness of the oil is measured with sufficient accuracy to assess the total oil volume in the slick, and the navigation of the aircraft is straightforward due to a reasonable swath width of the imaging radiometer.

Concerning the low flying profiling mode, a few points should be made: 1) The thickness of the oil is measured with great accuracy and resolution. 2) Detailed thickness distributions within the oil slick can be measured. 3) Navigation of the aircraft is delicate over limited sized slicks. 4) The measured profiles must in some semi-automatic way be superimposed on imagery of the oil slick (IR/UV scanner for example) taken simultaneously from the same aircraft, if they are to be of any use.

\section{Recommendations for a Practical System}

The system must be imaging. In just one pass the areal extent of the oil is directly depicted and the thickness of the oil is measured, hence, an assessment of the total oil volume within the slick is possible. The navigation of the aircraft over the oil spill is straightforward due to a reasonable swath width of the imaging radiometer.

The system must comprise two channels: one in the 30$40 \mathrm{GHz}$ range and one in the $10-18 \mathrm{GHz}$ range. The $30-$ $40 \mathrm{GHz}$ radiometer may be regarded as the prime channel. It gives good spatial resolution for a reasonably sized antenna, it resolves the thickness of thin oil films, and it gives, in many cases, good estimates of oil volume. But for some films also encountered in real life, a lower fre-

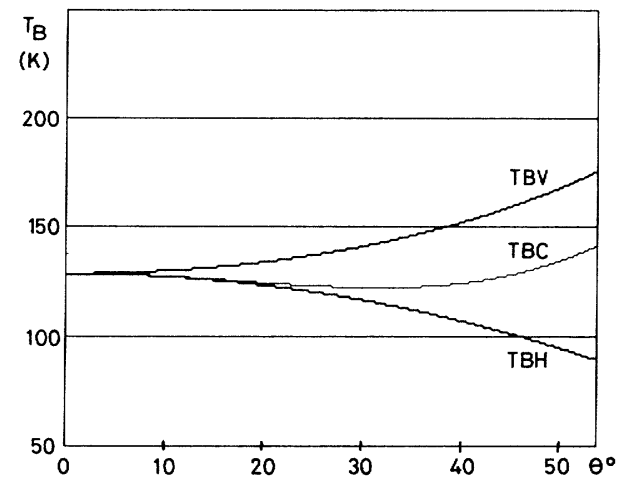

Fig. 12. 34- GHz brightness temperature of the sea as a function of scan angle. TBV : vertical, TBH : horizontal, TBC : mixed polarization.

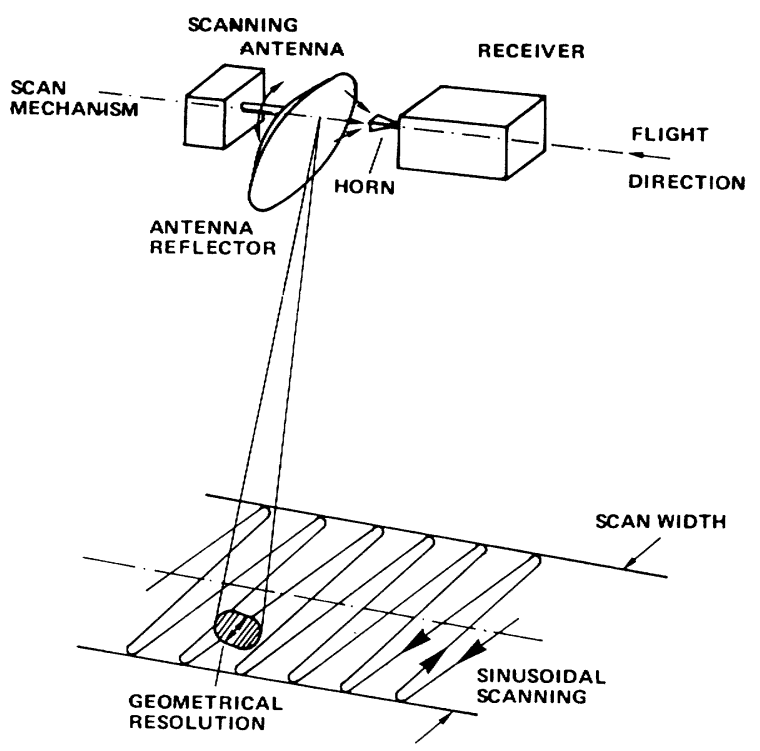

Fig. 13. Line scanner.

quency is needed to obtain accurate volumetric determination. A frequency of $10-18 \mathrm{GHz}$ is believed to be a good compromise: A reasonable distance to the prime frequency, while lower frequencies will suffer from coarse ground resolution for practical antenna sizes, and will only be valuable in extreme oil spill cases.

The conical antenna scan certainly has a great advantage over the line scan: It keeps the angle of incidence constant over the swath. This feature is much appreciated in research systems. But in general, a line scanner is much easier to build into an aircraft. So, for practical reasons, the line scanner should be used whenever compatible with the measurement requirements.

The brightness temperature of the sea is at both horizontal and vertical polarization strongly dependent on incidence angle (see Fig. 12). Considering the line scanner shown in Fig. 13, where a vertically polarized horn illuminates the offset parabolic reflector, a high degree of polarization mixing takes place as soon as the antenna beam scans off nadir.

Also in Fig. 12 is shown how the resulting mixed polarization brightness temperature varies with scan angle 


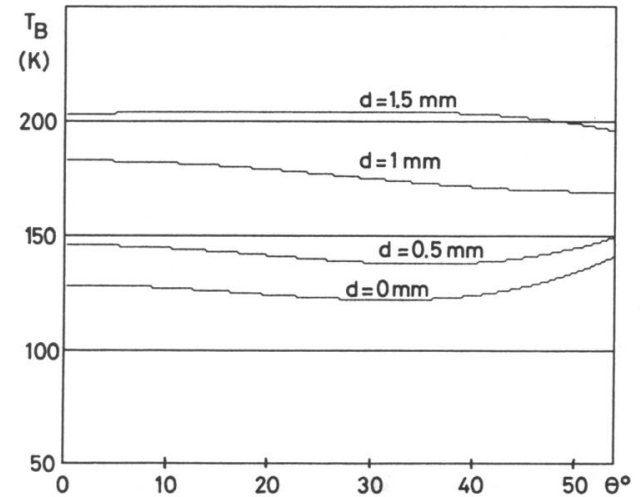

Fig. 14. Brightness temperature as a function of scan angle (at $34 \mathrm{GHz}$ ) with oil slick thickness as a parameter. Mixed polarization.

out to $\pm 55^{\circ}$. To further enlighten the subject, Fig. 14 shows how the brightness temperature varies with scan angle, not only for the unpolluted sea but also for an oilcovered sea (with slick thickness as parameter). The variations are small and gentle, and easy to correct for in the data analysis algorithms.

A system like the one illustrated in Fig. 13 is under development at TUD and in Danish industry. It comprises a dual-frequency total power receiver (37 and $11 \mathrm{GHz}$ ), a scanning offset parabolic reflector, and on-line digital data processing and image presentation. It is intended for installation in even small aircraft.

\section{REFERENCES}

[1] J. P. Hollinger and R. A. Menella, "Oil spills: Measurements of their distributions and volumes by multifrequency microwave radiometry," Science, vol. 181, pp. 54-56, July 1973.
[2] J. P. Hollinger, "The determination of oil thickness by means of multifrequency passive microwave techniques," Naval Research Lab., Washington DC, NRL Memor. Rep. 2953, June 1974.

[3] B. E. Troy and J. P. Hollinger, "The measurement of oil spill volume by a passive microwave imager," Naval Research Lab., Washington DC, May 1977.

[4] H. Bach, "The reflection from and transmission through a homogeneous plate of a plane electromagnetic wave," Electromagnetics Institute, Lyngby, Denmark, R134, Dec. 1974.

[5] J. F. Paris, "Salinity survey using an airborne microwave radiometer," in Proc. 8th Conf. Remote Sensing Environment (Ann Arbor, MI), pp. 665-676, Oct. 1972.

[6] A. Lääperi, "Experimental results from oil thickness measurements with a microprocessor controlled microwave radiometer," presented at IGARSS'83, San Francisco.

[7] E. I. Parkhomenko, Electrical Properties of Rocks. New York: Plenum, 1967, p. 20.

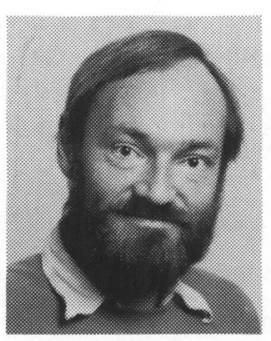

Niels Skou (S'78-M'84) received the M.Sc. degree in electrical engineering in 1972 and the $\mathrm{Ph} . \mathrm{D}$. degree in the field of microwave radiometers and radiometer measurements in 1981, both from the Technical University of Denmark.

In 1972, he joined the Electromagnetics Institute of the Technical University. After three-years' work with the development of radar systems for measuring the ice sheets in Greenland and Antarctica, his interest turned toward microwave radiometry. From 1975 to 1979 , he developed the scanning multifrequency airborne radiometer system of the Electromagnetic Institute. His current research deals with microwave remote sensing primarily within radiometry. His current subjects are radiometer measurements of sea ice and oil pollution on the sea, spaceborne radiometer systems, and development of new systems for specific operational purposes. 